\title{
CORRECTION TO THE PAPER
}

"HAAR SERIES" [1]

V. G. Krotov

An error is contained in the proof of Lemma 1 of the author's paper [1]; furthermore, Lemma 1 is false. In this connection the formulations of certain assertions in the article require correction. In Theorem 1 condition (5) needs to be replaced by the stricter requirement.

$$
\sum_{n=n}^{\infty} \omega\left(2^{-k}\right)=O\left\{\omega\left(2^{-n}\right)\right\} \text { as } n \rightarrow \infty \text {. }
$$

Under this assumption the proof goes through in the same way as for Theorem 10 of [2]

The question of the validity of Theorems 4 and 5 in [1] remains open. Together with them we have the valid statement: if $\omega(\delta)$ satisfies condition $(B)$, then for every function $\mathbb{f}(\mathrm{x}) \in \mathrm{C}(0,1)$, for which $\lim _{\delta \rightarrow 0} \omega(\delta$, f) $/ \omega(\delta)>0$, there is fulfilled the relation

$$
a_{m}(f) \circ \neq\left\{m^{\frac{1}{2}} \omega\left(\frac{1}{m}\right)\right\} \quad \text { as } m \rightarrow \infty
$$

The proof of this fact is carried out in the same way as for Theorem 4 in [1], except that instead of the erroneous Theorem 1 its corrected version above is used.

\section{LITERATURE CITED}

1. V. G. Krotov, "Haar series," Sibirsk. Matem. Zh., 14, No. 1, 111-127 (1973). 14, No. 1, 111-127.

2. B. I. Golubov, "On Fourier series of continuous functions with respect to a Haar system," Izv. Akad. Nauk SSSR, Seriya Matem., 28, No. 6, 1271-1296 (1964).

Translated from Sibirskii Matematicheskii Zhurnal, Vol. 16, No. 2, pp. 417-418, March-April, 1975.

(c) 1975 Plenum Publishing Corporation, 227 West 17 th Street, New York, N.Y. 10011. No part of this publication may be reproduced stored in a retrieval system, or transmitted, in any form or by any means, electronic, mechanical, photocopying, microfilming, recording or otherwise, without written permission of the publisher. A copy of this article is available from the publisher for 15.00 . 